\title{
Evaluation and Visualization of the Right Ventricle Using Three-Dimensional Echocardiography
}

\author{
Yui Ito, Yusaku Kamiya, Azuma Ikari, \\ and Katsuaki Toyoshima
}

Keywords

Pulmonary hypertension · Three-dimensional echocardiography $\cdot$ Right ventricular function

As neonatal right ventricular (RV) function undergoes transition from fetal to neonatal circulation, evaluation of the neonatal right ventricle is important. We analyzed the RV function of three infants with persistent pulmonary hypertension of the newborn (PPHN) using three-dimensional transthoracic echocardiography (3D echo) and herein report the results.

Patient 1 was a boy born at 40 weeks (weight, 3284 g; Apgar score (Ap), 7/8) with neonatal asphyxia, meconium aspiration syndrome, and PPHN. His oxygen saturation increased with inhaled nitric oxide (iNO) therapy; 3D echo was performed 6 and $12 \mathrm{~h}$ after iNO therapy.

Patient 2 was a girl born at 41 weeks (weight, 3010 g; Ap, 1/6) with neonatal asphyxia, neonatal pneumonia, and PPHN. She underwent iNO therapy and improved; 3D echo was performed before and after iNO therapy.

Patient 3 was a boy with congenital cystic adenomatoid malformation and hydrops fetalis. He was born by cesarean section at 35 weeks with uncontrollable pleural fluid and ascites. His pulmonary hypertension $(\mathrm{PH})$ and respiratory condition did not improve even after thoracentesis, lobectomy, and sildenafil. He died $27 \mathrm{~h}$ after birth. Echocardiography was performed after lobectomy.

In each case, we performed 3D echo with an EPIQ system and X7-2 transducer (Philips Healthcare, Amsterdam, Netherlands) and analyzed the images with a TomTec system (TomTec Imaging Systems, Unterschleißheim, Germany) (Fig. 28.1). 3D data were acquired in a full-volume data set from the four-chamber

Y. Ito $(\triangle) \cdot$ Y. Kamiya $\cdot$ A. Ikari $\cdot$ K. Toyoshima

Neonatology, Kanagawa Children's Medical Center, Yokohama, Kanagawa, Japan 
Fig. 28.1 3D RV image by a TomTec System

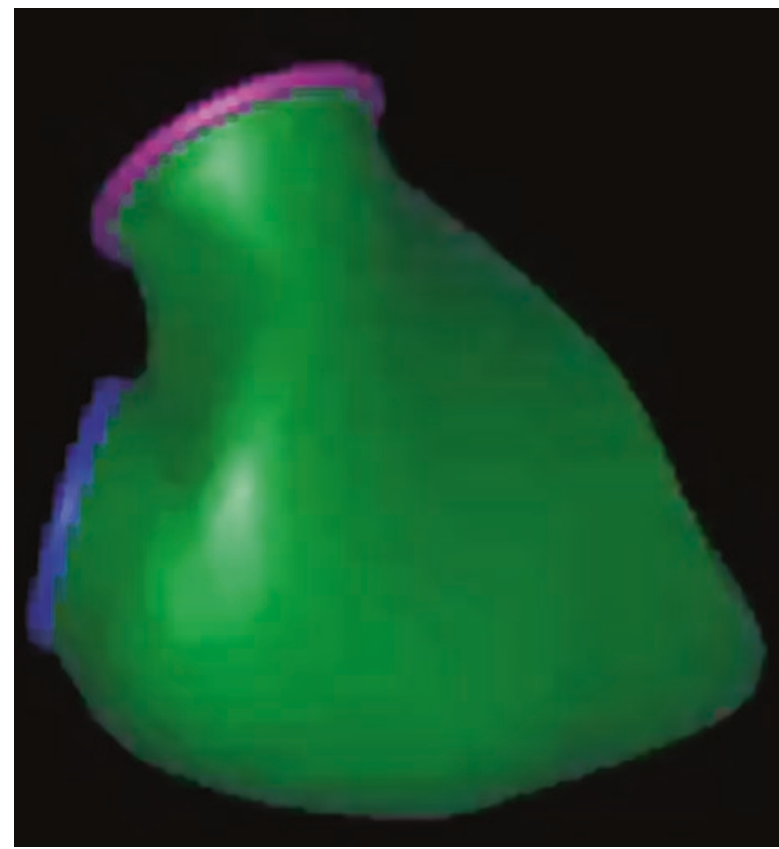

CASE1

\begin{tabular}{|l|l|l|} 
& $\begin{array}{l}\text { iNO } \\
6 \mathrm{~h}\end{array}$ & $\begin{array}{l}\text { iNO } \\
12 \mathrm{~h}\end{array}$ \\
\hline $\begin{array}{l}\text { RVEDV } \\
(\mathrm{ml})\end{array}$ & 5.7 & 5.7 \\
\hline $\begin{array}{l}\text { RVSV } \\
(\mathrm{ml})\end{array}$ & 1.6 & 2.3 \\
\hline $\begin{array}{l}\text { RVEF } \\
(\%)\end{array}$ & 28 & 40 \\
\hline
\end{tabular}

CASE2

\begin{tabular}{|l|l|l|}
\hline & $\begin{array}{l}\text { Before } \\
\text { iNO }\end{array}$ & After iNO \\
\hline $\begin{array}{l}\text { RVEDV } \\
(\mathrm{ml})\end{array}$ & 5.1 & 4.9 \\
\hline $\begin{array}{l}\text { RVSV } \\
(\mathrm{ml})\end{array}$ & 1.4 & 1.9 \\
\hline $\begin{array}{l}\text { RVEF } \\
(\%)\end{array}$ & 28 & 39 \\
\hline
\end{tabular}

CASE3

\begin{tabular}{|l|l|}
\hline & \multicolumn{1}{|c|}{ CPAM } \\
\hline $\begin{array}{l}\text { RVEDV } \\
(\mathrm{ml})\end{array}$ & 4.8 \\
\hline $\begin{array}{l}\text { RVSV } \\
(\mathrm{ml})\end{array}$ & 3.5 \\
\hline $\begin{array}{l}\text { RVEF } \\
(\%)\end{array}$ & 27 \\
\hline
\end{tabular}

Fig. 28.2 Data of RVEDV, RVSV, RVEF in Cases 1-3

apical view. The frame rate was $50 \mathrm{~Hz}$. In Patient 1, the right ventricular enddiastolic volume (RVEDV) was the same $(5.7 \mathrm{ml})$ at 6 and $12 \mathrm{~h}$ after starting iNO therapy; however, the right ventricular stroke volume (RVSV) and right ventricular ejection fraction (RVEF) increased from 1.6 to $2.3 \mathrm{ml}$ and from $28 \%$ to $40 \%$, respectively. In Patient 2, the RVEDV slightly decreased from 5.1 to $4.9 \mathrm{ml}$ before and after iNO therapy. The RVSV and RVEF increased from 1.4 to $1.9 \mathrm{ml}$ and from $28 \%$ to $39 \%$, respectively. In Patient 3, the RVEDV was $4.7 \mathrm{ml}$, RVSV was $3.5 \mathrm{ml}$, and RVEF was $27 \%$ (Fig. 28.2).

The RVEF increased in Patients 1 and 2 following the improvement of $\mathrm{PH}$ and remained low in Patient 3. This may suggest that RVEF is significantly correlated 
with PH. Murata et al. [1] reported that RVEF measured by 3D echo could help to noninvasively predict the clinical outcomes of PH. Thus, 3D echo data might be useful for evaluating patients' cardiac condition and choosing treatment.

\section{Reference}

1. Murata M. Prognostic value of three-dimensional echocardiographic right ventricular ejection fraction in patients with pulmonary arterial hypertension. Oncotarget. 2016;7(52):86781-90. https://doi.org/10.18632/oncotarget.13505.

Open Access This chapter is licensed under the terms of the Creative Commons Attribution 4.0 International License (http://creativecommons.org/licenses/by/4.0/), which permits use, sharing, adaptation, distribution and reproduction in any medium or format, as long as you give appropriate credit to the original author(s) and the source, provide a link to the Creative Commons license and indicate if changes were made.

The images or other third party material in this chapter are included in the chapter's Creative Commons license, unless indicated otherwise in a credit line to the material. If material is not included in the chapter's Creative Commons license and your intended use is not permitted by statutory regulation or exceeds the permitted use, you will need to obtain permission directly from the copyright holder. 